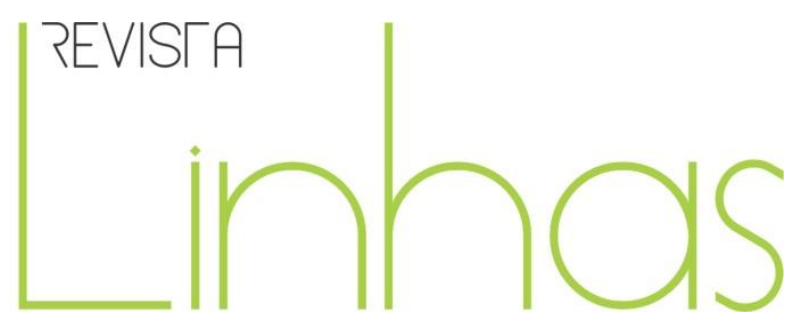

\title{
El Ministro de Educación en la escuela. El noticiario franquista NO- DO y las construcciones escolares en España ${ }^{1}$
}

\section{Resumen}

Este artículo trata sobre la política de construcciones escolares del franquismo a partir de los noticiarios del NO-DO como fuente de información. El análisis se centra en los noticiarios del NO-DO en los que el Ministro de Educación va a las escuelas de primaria. El artículo utiliza el NO-DO como fuente de información y los contrasta con la prensa escrita. El protagonismo del Ministro de Educación en el NODO es un reflejo de su política educativa, que respecto a las construcciones escolares estuvo marcada por numerosas deficiencias.
Josep Casanovas Prat

Universitat de Vic - UCC -

España

josep.casanovas@uvic.cat

Eulàlia Collelldemont Pujadas

Universitat de Vic - UCC -

España

eulalia@uvic.cat

Palabras Clave: Historia de la Educación. Franquismo. Noticiarios. Política educativa. NO-DO. Construcciones escolares.

\section{Para citar este artigo:}

PRAT, Josep Casanovas; PUJADAS, Eulàlia Collelldemont. El Ministro de Educación en la escuela. El noticiario franquista NO-DO y las construcciones escolares en España. Revista Linhas. Florianópolis, v. 21, n. 47, p.45-72, set./dez. 2020.

DOI: 10.5965/1984723821472020045

http://dx.doi.org/10.5965/1984723821472020045

\footnotetext{
${ }^{1}$ Este artículo es un resultado del proyecto de investigación "ARAEF. Análisis de las representaciones audiovisuales de la educación en documentales y noticiarios durante el franquismo" (Ref. EDU2017-89646-R AEI/FEDER, UE). El cual forma parte del Programa Estatal de Investigación, Desarrollo e Innovación (I+D+i) Orientada a los Retos de la Sociedad, en el marco del Plan Estatal de Investigación Científica y Técnica y de Innovación 2013-2016.
} 


\section{The Minister of Education in the school. The Francoist newsreel NO-DO and school buildings in Spain}

\begin{abstract}
This article is about the school building policy of the Franco regime from a source of information such as the newsreel of the NODO. The analysis focuses on the newsreels of the NO-DO in which the Minister of Education goes to primary schools. The article uses the NO-DO as a source of information and contrasts them with the written press. The role of the Minister of Education in the NO-DO is a reflection of its educational policy, which regarding school buildings had numerous deficiencies.
\end{abstract}

Keywords: History of Education. Francoism. Newsreels. NO-DO. Education policy. School buildings.

\section{O Ministro da Educação na escola. O noticiário franquista NO-DO e as construções escolares na Espanha}

\section{Resumo}

Este artigo aborda a política de construções escolares do franquismo, considerando os noticiários do NO-DO como fontes de informação. A análise se centra nos noticiários do NO-DO em que o Ministro da Educação vai às escolas do ensino fundamental. $O$ artigo utiliza o NO-DO como fonte de informação e o compara com o jornal impresso. O protagonismo do Ministro da Educação no NO-DO é um reflexo de sua política educativa que, em relação às construções escolares, esteve marcada por numerosas deficiências.

Palavras-chave: História da Educação. Franquismo. Noticiários. Política educativa. NODO. Construções escolares. 


\section{Introducción}

Una disposición de la Vicesecretaría de Educación Popular, de 17 de diciembre de 1942, creaba una entidad oficial denominada NO-DO (Noticiarios y Documentales Cinematográficos), que tenía el monopolio de la producción y la exhibición de noticiarios en todos los cines de España. Esta situación se mantuvo hasta el 22 de agosto de 1975, fecha en que se suprimió la obligatoriedad de exhibir el NO-DO, aunque la edición de su Noticiario se prolongó hasta finales de 1981. En este largo periodo, el NO-DO produjo un gran caudal de noticias de todo tipo, entre las cuales nos proponemos analizar aquellas en que el Ministro de Educación protagoniza la inauguración de escuelas de primaria, dando así más relevancia al evento. Estas noticias eran la imagen de la actuación política que quería transmitir el Ministerio de Educación. A través de estos NO-DO, nuestro objetivo general es el de conocer la propaganda del franquismo sobre la política de construcciones escolares.

Durante la dictadura del general Franco (1939-1975), el NO-DO fue un instrumento de propaganda audiovisual al servicio del ideario franquista, con abundante información institucional de corte propagandístico, pero también con atisbos de otra realidad al margen del discurso oficial que, en conjunto, han convertido el NO-DO en un "memorial del franquismo" tal como lo califican Rafael Tranche y Vicente Sánchez-Biosca (2006, pp. 1618). En este artículo partiremos de noticias del NO-DO claramente institucionales, como son las que cuentan con la presencia de un ministro de educación en una escuela. Estas noticias tienen el interés de mostrar el discurso oficial sobre las construcciones escolares en España durante el franquismo. Una información que contrastaremos con la prensa escrita de la época y en menor medida con otras fuentes históricas (documentos o estudios sobre cada caso), para contextualizar las noticias y fijarnos en qué aspectos se centra el NO-DO y qué aspectos no contempla. Se trata también de intentar esclarecer entre realidad y propaganda, como forma de dar una aproximación más ajustada de la realidad del momento.

Las investigaciones sobre el NO-DO cuentan con estudios generales, los ya mencionados Rafael Tranche y Vicente Sánchez-Biosca han realizado sin duda la principal 
obra de referencia, editada por primera vez en el año 2001. En los últimos años han empezado a publicarse estudios que analizan de forma parcial los contenidos del NO-DO, entre los cuales se encuentran nuestras investigaciones sobre educación y NO-DO, los resultados de la misma pueden consultarse en la página web del MUVIP (Museu Universitari Virtual de Pedagogia), al que está vinculado nuestro grupo de investigación. Entre los estudios temáticos del NO-DO cabe mencionar los relacionados con el deporte, un tema muy recurrente en los noticiarios del franquismo (GÓMEZ, 2015; GUTIÉRREZ, JIMÉNEZ, GÓMEZ \& IZQUIERDO, 2016; SIMÓN, 2019), pero también sobre la vertiente educativa de la Sección Femenina (MOLINA \& SANCHIDRIÁN, 2019). Existe aún un gran abanico de posibilidades de analizar temáticamente el NO-DO, entre las cuales se encuentra el análisis de la presencia del Ministro de Educación en la escuela tratada en este artículo.

La aparición del Ministro de Educación en los NO-DO pretendía integrar el personaje en el contexto político y educativo del franquismo. Buena parte de los noticiarios del NODO protagonizados por el Ministro de Educación tenían que ver con la Universidad o la investigación científica, mientras que la escuela primaria tuvo muy poca representación, en una clara muestra de que el ámbito educativo al que se daba mayor interés propagandístico era la educación superior. Entre las noticias relacionadas con la educación primaria, el tema de las construcciones escolares fue sin duda el que acaparó mayor atención por parte del NO-DO. Muy pocas secuencias del NO-DO muestran imágenes de maestros y alumnos en la escuela, cosa que evidencia la escasa predisposición de estos noticiarios audiovisuales hacia la práctica escolar, tal como ya apuntábamos en un estudio inicial sobre los NO-DO y la práctica escolar (CASANOVAS \& PADRÓS, 2018).

En los NO-DO relacionados con las escuelas de educación elemental o básica, los protagonistas de las informaciones no son los maestros ni sus alumnos, sino el edificio escolar y las autoridades que se reciben en cada escuela. Entre estas autoridades, durante el franquismo nos fijamos en los diferentes ministros de educación que acuden a inaugurar escuelas y exposiciones sobre centros escolares. La presencia del Ministro de Educación en los noticiarios del NO-DO sobre escuelas es un hecho noticiable, extraordinario por ser poco frecuente que la máxima autoridad educativa acuda a una escuela. Esta presencia del 
Ministro de Educación es también un indicador de la relevancia o importancia propagandística que se daba desde su ministerio a esta etapa educativa y a la necesidad de propagar su política en torno a las construcciones escolares.

La representación en los NO-DO de las autoridades que presiden las inauguraciones de escuelas sigue un patrón narrativo muy similar al utilizado en otros documentales y noticiarios anteriores al franquismo. Estos noticiarios del NO-DO son conceptualmente muy similares a las noticias de actualidad filmadas durante la dictadura del General Primo de Rivera (1923-1930) que hemos recogido en otro estudio (CASANOVAS \& COLLELLDEMONT, 2016). En ambas dictaduras, Primo de Rivera y Franco, el edificio de la escuela y las autoridades (civiles, militares y religiosas) son los protagonistas de las noticias filmadas sobre escuelas. Formalmente hay algunos cambios, resultado en parte de mejoras técnicas de la cinematografía, con la introducción del sonido y la mejora de las cámaras, los noticiaros del NO-DO serán más dinámicos, con un montaje acelerado a base de planos breves acompañados de comentarios en off.

Después de un primer apartado de conjunto sobre Franco y sus ministros, trataremos tres de los cuatro períodos que, desde una perspectiva ministerial Antonio Viñao (2014, p. 25), distingue la historia de la educación durante el franquismo. El primer periodo de Guerra Civil y el ministerio de Sáinz Rodríguez (1936-1939) no lo tratamos al no existir aún el NO-DO. Las tres etapas restantes, que analizaremos de forma sucesiva, son la del nacionalcatolicismo extremo del ministro Ibáñez Martín (1939-1951), el periodo de transición del nacionalcatolicismo a la tecnocracia autoritaria con los ministerios de Ruiz Giménez, Rubio García-Mina y Lora Tamayo (1951-1968) y, finalmente, la etapa de la Ley General de Educación de 1970 bajo el ministerio de Villar Palasí y los posteriores ministros contrarreformistas (1968-1975). 


\section{Franco y sus ministros en el NO-DO}

En el marco de una dictadura totalitaria, uno de los primeros objetivos de los noticiarios del NO-DO fue el de contribuir a crear un retrato carismático de la figura de Francisco Franco. Tal como señala Miguel Ángel Hernández en su libro sobre el NO-DO al servicio del Estado unitario, la exaltación de la victoria militar lograda por Franco fue uno de los "ejes fundamentales de la propaganda cinematográfica destinada a legitimar su poder" (2003, p. 195). Se presentaba Franco como un general victorioso, que aparecía con frecuencia en el NO-DO. Rara era la semana en la que no aparecía Franco en la pantalla de los noticiarios del NO-DO, pero también algún de sus ministros participando de actos oficiales generales o relacionados con su gestión ministerial.

Consolidado el régimen franquista y el poder personal de Francisco Franco a partir de los años cincuenta, ya no se necesitaba reforzar la figura del dictador en los noticiarios del NO-DO, y como consecuencia la imagen de Franco aclamado por las multitudes fue difuminándose, sin dejar de perderse. En su lugar, en palabras de Araceli Rodríguez, "se proyectaba la figura de un Jefe de Estado que hacía posible la reconstrucción económica de España, con el consiguiente agradecimiento del pueblo" (2008, p. 62). La labor de los ministros en el NO-DO también estaba en plena sintonía con la idea de reconstrucción y modernización de España.

Las informaciones sobre actos de inauguración y las visitas tenían un mismo modelo narrativo y audiovisual, el cual servía para todo tipo de inauguración o visita, ya podía ser un embalse, unos bloques de viviendas, una fábrica o una escuela. Los editores de NO-DO impusieron un modelo de relato que exhibía avances a propósito de la inauguración y visita oficial de las autoridades. Las piezas del NO-DO sobre inauguraciones y visitas seguían una misma pauta narrativa, con una serie de rasgos audiovisuales comunes. Visualmente, se establecía una narración lineal, sencilla, con un montaje a base de cortes. Identificaba a las autoridades protagonistas y se concentraba en la descripción de la obra inaugurada. Era habitual que en una misma visita a una población se inaugurasen o visitasen diferentes edificios, entre ellos escuelas. 
Sigue completamente el patrón la noticia mencionado el NO-DO 564 A, de 26 de octubre de 1953, con el título general de “Cádiz". Las imágenes muestran la visita del dictador Francisco Franco a esta ciudad andaluza, donde vestido de militar inaugura una escuela y almacén frigorífico en el muelle pesquero. La primera secuencia del NO-DO es de la inauguración del grupo escolar, situado en el reconstruido barrio de San Severiano, destruido en el año 1947 por una explosión accidental de un depósito de minas submarinas de la armada española, que arrasó el mencionado barrio provocando más de un centenar de víctimas mortales y numerosos heridos. Es significativo que el NO-DO empiece con imágenes de la inauguración de la escuela Sagrada Familia del barrio de San Severiano, porque sin mencionarlo nos remite a los trágicos sucesos de 1947, queriendo mostrar que en 1953 han sido resueltos por el mismo Franco. Por documentación, sabemos que, en realidad, Franco inauguró primero el almacén frigorífico y la escuela después. La prensa escrita destacaba en sus titulares otros aspectos de la visita, por ejemplo, el diario $A b c$ de 16 de octubre de 1953, tiene como titular principal unas palabras de Franco sobre la importancia del mar, dejando la inauguración de la escuela como última parte de una noticia larga noticia escrita que ocupa cuatro páginas.

Durante las inauguraciones en Cádiz, Franco estaba acompañado por diversas autoridades, entre las que se encuentran varios ministros, comenta el narrador del NO-DO, sin mencionar cuales. Entre los ministros de viaje en Cádiz había el Ministro de Gobernación y el de Marina (no hemos identificado al Ministro de Educación), pero todas las autoridades quedan eclipsadas por Franco. La noticia finaliza con escenas de una multitud de personas que aplaude fervorosamente a Franco, que desfila en comitiva por calles de Cádiz hasta llegar al Ayuntamiento, donde desde su balcón dirige unas palabras a los miles de personas que le ovacionan sin cesar en una plaza completamente llena. En estas escenas se ven numerosas pancartas que rezan frases de gratitud hacia Franco, entre las que se pueden leer con claridad las siguientes: "Solo con Franco Cádiz ha salido de la miseria" o "Como nos obliga nuestra historia Cádiz está dispuesto a darlo todo por España junto a Franco". Un relato cinematográfico que subraya el significado ideológico del acto. Un montaje de una noticia con ciertos planos, elementos sonoros, ritmo, locución con un esquema narrativo que introducía una lectura favorable a la plena adhesión a Franco. 
Este esquema de narrativa de la inauguración de la escuela de Cádiz es similar al de otras piezas del noticiario NO-DO, como por ejemplo otra inauguración de una escuela en el mismo año 1953, realizada en Burgos, que recoge el NO-DO 553 B, de 10 de agosto de 1953, con título “Franco en Burgos. El Generalísimo inaugura una fábrica de papel moneda. Un nuevo grupo escuela que albergará a un millar de alumnos". La noticia del NO-DO incluye, por este orden y como indica el título, la inauguración de una nueva fábrica de papel moneda y la inauguración de un nuevo grupo escolar que lleva el nombre del mismo Francisco Franco. La crónica de la prensa escrita ( $A b c, 29-7-1953$, p. 9) nos indica que aquel día Franco presidió tres inauguraciones sucesivamente: primera, una escuela técnicoprofesional (que no aparece en el NO-DO); segunda, el grupo escolar Francisco Franco; tercera, la fábrica de papel moneda. Es esta última con la que empieza el NO-DO, con abundantes imágenes de su interior, mientras que la escuela de primaria queda relegada a un segundo lugar y el centro de formación profesional ni tan solo se muestra en el NO-DO. Una vez más, la selección y el orden de los contenidos nos demuestra la intencionalidad de la noticia, en este caso destacando una fábrica destinada a "independizar España" del exterior en materia de papel moneda, respeto a inauguración de dos escuelas.

A diferencia de Cádiz, en la noticia "Franco en Burgos" no aparece ningún baño de multitudes hacía Franco, sin que esto represente una pérdida de protagonismo del mismo en las imágenes del NO-DO. Entre las autoridades que acompañan Franco y su esposa de viaje en Burgos, la voz en off del NO-DO menciona a los ministros de hacienda, educación nacional y obras públicas. Pero su presencia en pantalla pasa desapercibida, Franco acapara el protagonismo de las escenas. A través de las imágenes de estos dos NO-DO es muy difícil percatarse de la presencia de los ministros, es gracias a la locución que los espectadores podían saber que entre las autoridades también había ministros.

Sobre el conocimiento y la popularidad de los ministros de Franco a través de los noticiarios del NO-DO, en el libro de Araceli Rodríguez sobre la imagen política del Régimen franquista en los noticiarios del NO-DO, la autora explica que las rápidas apariciones colectivas de autoridades en el NO-DO no permitían a los espectadores identificar bien a los ministros. Continúa explicando que los espectadores se "familiarizaron poco a poco con los ministros", "a fuerza de verlos protagonizar noticias” (RODRíGUEZ, 2008, p. 115). En 
este proceso propagandístico, los ministros de educación José Ibañez Martín, Joaquín Ruíz Jimenez y José Rubio fueron entre los años 1943 a 1959 unos de los rostros más populares en el NO-DO (RODRÍGUEZ, 2008, p. 117). Entre estos años, según los cálculos de Araceli Rodríguez (2008, p. 118-119) los ministros de Asuntos Exteriores fueron los que protagonizaron más noticias del NO-DO, 113 en total seguidos de los ministros de Educación con 100 noticias. Muestra que la cartera de Educación fue uno de los ámbitos que concentraron mayor interés en el NO-DO. Los temas de las noticias del NO-DO protagonizadas por el ministro de Educación son muy variados, tratan sobre universidades, investigación científica, visitas, inauguraciones, conmemoraciones y distinciones diversas.

\section{El nacionalcatolicismo extremo del ministro Ibáñez Martín (1939-1951)}

En el año 1939, una vez terminada la Guerra Civil, Franco reorganizó su gobierno y nombró a José Ibáñez Martín como Ministro de Educación Nacional. Se trataba, según Manuel Tuñón de Lara (1990, p. 19) de un “oscuro profesor de Geografía, más conocido por su fervoroso militantismo en Acción Católica y por sus buenas relaciones con la dictadura de Primo de Rivera". El ministro Ibáñez Martín fue el encargado de volver a dejar la escuela bajo la hegemonía eclesiástica, promulgó en 1945 la Ley de Educación Primaria, pero el balance de su gestión fue muy pobre. Al final de su mandato se había reducido el número de escuelas en España, el presupuesto del Ministerio de Educación también se había reducido y sobre plazas escolares Ibañez Marín "tan sólo había sido capaz de escolarizar a la mitad de la población escolar" (TUÑóN, 1990, p. 20).

A diferencia de los ministros de educación que lo sucedieron, José Ibañez Martín tuvo la responsabilidad directa sobre los medios de comunicación, de él dependían los Servicios de Información y Prensa del Estado. La tutela de los mismos quedó en manos de un ministro católico, que responde al prototipo de hombre del Nuevo Régimen franquista, al margen de los falangistas. En la base del NO-DO estaba una orientación educativa de signo nacional-católica, que convirtió los noticiarios del NO-DO en un "púlpito" privilegiado, un concepto deliberadamente simbólico, habida cuenta del color confesional del paisaje español del momento (RODRíGUEZ, 1999, p. 17). 
Las inauguraciones de escuelas protagonizadas en los noticiarios del NO-DO por el ministro José Ibañez son muy escasas y se concentran en los últimos años de su mandato. Esta escasez es un reflejo de la falta de una política de construcciones escolares y el poco interés por dotar de centros públicos de educación primaria, en favor de los colegios religiosos. La selección de dos noticias del NO-DO, una sobre un centro en Barcelona y otra en Valencia, nos muestra que el Ministerio de Educación iba a remolque de los municipios, en lo que podemos apreciar como una apropiación ministerial de unas iniciativas municipales.

Hasta el año 1948 no encontramos una noticia en el NO-DO de la inauguración de una escuela protagonizada por el Ministro de Educación Nacional. Se trata de la inauguración por parte de José Ibáñez del nuevo edificio de la Escuela del Mar, en Barcelona, recogida en una noticia del NO-DO 310 A, de 13 de diciembre de 1948, sobre la que no se ha conservado el audio. Existe una noticia anterior sobre la inauguración de diversos edificios, entre ellos una escuela, en el municipio de Puebla de la Sierra en Madrid en el año 1947 (NO-DO, 259 A, 1947), solo con la asistencia de autoridades provinciales, sin la participación de ningún ministro. La inauguración de la Escuela del Mar no era el principal motivo de la visita en Barcelona del ministro José Ibáñez, pero aun así está recogida en una noticia del NO-DO centrada exclusivamente en esta inauguración. El principal motivo de la estancia de José Ibáñez en Barcelona era el de recibir en nombre del dictador, Francisco Franco, unas reliquias de San José de Calasanz, procedentes de Roma, que llegaron el 24 de noviembre de 1948 al puerto de Barcelona en un barco de la armada española. Las imágenes de una noticia exclusiva del NO-DO recogen la llegada al puerto, la recepción por parte del ministro José Ibáñez y el recorrido en procesión de las reliquias por las calles de la ciudad condal (NO-DO, 309 A, 1948). Existen pues dos noticias diferentes de dos noticiarios del NO-DO, ambas con el título genérico de "Barcelona", que recogen la estancia del Ministro de Educación Nacional en Barcelona.

Antes de volver en avión a Madrid, el ministro José Ibáñez inauguró el nuevo edificio de la Escuela del Mar en el barrio del Guinardó de Barcelona. La Escuela del Mar se había creado en el año 1922 por iniciativa de la comisión de cultura del Ayuntamiento de Barcelona. Dirigida por el pedagogo Pere Vergés era un centro innovador, seguía los 
principios del higienismo, con una enseñanza activa practicada en el aire libre. El primer edificio de la Escuela del Mar estaba situado en la playa de pescadores del barrio de la Barceloneta. En el año 1938 este edificio de madera quedó completamente destruido, a causa de un incendio provocado por un bombardeo de la aviación fascista. Un documental en el que participan diversos antiguos alumnos trata de la historia de este centro, así como de su destrucción (CORBERA, MOREJÓN \& OLSINA, 2010). La escuela fue trasladada primero a un edificio en la montaña Montjuïc hasta la inauguración del nuevo edificio.

Las imágenes del NO-DO 310 A, de 13 de diciembre de 1948, sobre la inauguración del nuevo edificio de la Escuela del Mar se concentran en el exterior del edificio. Empiezan con un plano general del exterior del edificio, a continuación, muestran la bendición del centro por parte del canónigo Serra Puig, que en representación del obispo de la diócesis bendice el edificio en la terraza central de la escuela. El ministro José Ibáñez acapara la atención al final de la bendición, con un plano corto, seguidamente las imágenes muestran el ministro subiendo unas escaleras exteriores acompañado por otras autoridades, el noticiario termina con una secuencia del interior del centro, mostrando diversas salas vacías. El edifico escolar y el ministro son el centro de esta noticia del NO-DO. Contrastando está información visual con la noticia escrita de La Vanguardia, de 27 de noviembre de 1948, descubrimos que el NO-DO no contiene el acto de inauguración que se realizó en la sala de música del centro, con un discurso del alcalde de Barcelona, el señor José María Albert Despujol, barón de Terrades, que dio unas llaves simbólicas del centro al consejo de alumnos, un obsequio por parte de los exalumnos del centro al alcalde y una representación musical y poética realizada por un grupo de alumnas. Unos protagonistas diferentes a los de la noticia del NO-DO que destaca el edificio, la bendición religiosa y el ministro José Ibáñez.

La información del NO-DO sobre la Escuela del Mar destaca la presencia del ministro, que acapara gran parte del protagonismo de la noticia, pero no da importancia o bien olvida otros aspectos interesantes de la inauguración. En las palabras dirigidas por el alcalde, recogidas en la prensa diaria, se menciona que la escuela fue destruida por un incendio, pero no que fue provocado por la aviación fascista italiana al servicio del ejército de Franco. Así pues, vemos una apropiación de la noticia de la inauguración de la Escuela 
del Mar por parte del ministro, pero también de una escuela por parte del franquismo. Años después, el NO-DO 1558 A de 1972, producido con motivo del cincuentenario de la Escuela del Mar, recoge diversas tomas con imágenes de práctica escolar en las terrazas exteriores del centro. Una noticia del NO-DO muy diferente a la de 1948, en la que sí que la escuela y su pedagogía activa característica son el tema de las imágenes. Una noticia en 1972 en unos momentos de cierta apertura del régimen franquista, en la que incluso la música de fondo es una canción cantada en catalán por niños, algo inimaginable en los inicios del NO-DO marcados por el nacionalcatolicismo extremo.

En 1949 en la ciudad de Valencia, un año después de la visita a Barcelona, el ministro José Ibáñez protagoniza una noticia en el NO-DO 364 B, de 26 de diciembre de 1949, que incluye la inauguración del grupo escolar Teodoro Llorente y de un campo de deportes. Se trata de la segunda inauguración de una escuela protagonizada por el Ministro de Educación Nacional, un grupo escolar de nueva creación que, a diferencia de la Escuela del Mar de Barcelona, no tiene un origen fundamentado en la pedagogía activa, sino en el nacionalcatolicismo imperante. En los dos NO-DO de inauguración pasa completamente desapercibido que estos dos centros escolares eran una iniciativa municipal, mientras que los dos destacan la presencia del Ministro de Educación Nacional. El colegio Teodoro Llorente se construyó en la calle Juan Llorens de Valencia, cerca del antiguo mercado de abastos, en una zona de gran crecimiento urbano durante la postguerra, en la que faltaban plazas escolares. El nuevo centro partía de un convenio entre el Ayuntamiento de Valencia y el Ministerio de Educación para la construcción de centros escolares en la ciudad de Valencia, a base de una participación por mitades en los gastos de construcción. El proyecto inicial del edificio escolar era del año 1944, el ayuntamiento empezó las obras de construcción sin terminar el edificio, mientras el barrio de alrededor del edificio en construcción crecía rápidamente. En el año 1948 se modificó el proyecto inicial aprobado por el ministerio, para sacar mayor partido del interior del edificio, atendiendo así a los requerimientos del arquitecto municipal, con el fin de convertirlo en una "escuela modelo", tal como consta en el expediente sobre el colegio Teodoro Llorente, conservado en el Archivo Municipal de Valencia. 
La escuela Teodoro Llorente se inauguró finalmente el 12 de diciembre de 1949 por el Ministro de Educación Nacional, José Ibáñez Martín, acompañado del arzobispo de Valencia, Marcelino Olaechea, el capitán general, José Monasterio, el gobernador civil, Ramón Laporta, el alcalde de la ciudad, José Manglano, así como otras autoridades, profesores de la Escuela Normal de Valencia y maestros del nuevo centro. El diario Las Provincias de 13 de diciembre de 1949 explicaba en primera página las características de la nueva escuela:

\begin{abstract}
Este grupo escolar, que lleva el nombre de «Teodoro Llorente», ha sido construido por el Ayuntamiento, según proyecto del arquitecto don Vicente Valls, y se han invertido en las obras dos millones de pesetas. El nuevo edificio es una obra magnífica, organizada para el funcionamiento de doce grados para niños, dos de ellos para párvulos. Tiene, además, personal especializado para enseñanzas especiales e iniciación profesional. El edificio tiene un magnífico salón de actos, biblioteca, salas de profesores, etcétera. Ocupa la planta baja y dos pisos, y posee un patio de recreo de más de mil metros cuadrados. Para comenzar las clases no resta más que la instalación del material pedagógico, en vías de adquisición mediante un concurso ya convocado.
\end{abstract}

El diario Las Provincias dedicaba más atención a la inauguración del colegio Teodoro Llorente que el diario falangista Levante, con una información muy breve sobre este tema, publicada también el 13 de diciembre de 1949. La participación de las autoridades y la descripción de la escuela era prácticamente la misma en ambos periódicos, pero Las Provincias, incluía más información del acto con un reportaje fotográfico de la inauguración en la contraportada y un grabado de Teodoro Llorente. Las Provincias se felicitaba que este poeta, fundador de su diario, pusiera nombre a un centro escolar, cosa que consideraba "el mejor monumento a la memoria del poeta" (13-12-1949, p.4).

El NO-DO 364 B, de 26 de diciembre de 1949, sobre el colegio Teodoro Llorente es una pieza sin el sonido original. Las imágenes de la noticia con el título de "El Ministro de Educación Nacional en tierras del Turia" empiezan con el acto de inauguración del centro docente. La secuencia empieza con una imagen de la fachada del centro, sobre la puerta principal se ve un gran escudo franquista con el águila imperial y la bandera española. Este escudo no se retiró del centro hasta el año 2017, 42 años después de la muerte del dictador, 
fue uno de los últimos símbolos franquistas presentes en edificios públicos de Valencia (Levante, 26-01-2017). En la calle frente a la escuela hay unos coches oficiales, un grupo de niños y algunos adultos que esperan, mantienen una actitud expectante que contrasta con las imágenes de entusiasmo y ovaciones de otras piezas del NO-DO más elaboradas. En el interior del centro se ve un aula, con pupitres alineados, una gran pizarra encima de la cual hay tres cuadros presididos por un crucifijo. Son tres cuadros difíciles de distinguir (en las fotos de la prensa se distinguen más claramente), con la figura de Franco y José Antonio a cada lado de una imagen religiosa. La simbología del régimen está muy presente. Las autoridades conversan en el interior del aula, bajo los símbolos políticos y religiosos.

Destaca la escena final, en la que el Ministro de Educación Nacional y el Arzobispo de Valencia se dan la mano ante la cámara, dos personajes que sobresalen entre el resto. Es una imagen que muestra la importancia que se dio a la Iglesia católica en la enseñanza primaria en esta etapa del nacionalcatolicismo. Las autoridades locales quedan totalmente relegadas a un segundo plano, entre ellas el alcalde de la ciudad, José Manglano, que a diferencia del arzobispo tuvo una intervención directa en la construcción del centro, ya que partía de una iniciativa municipal.

Después de la inauguración del colegio Teodoro Llorente, la noticia sobre la visita del Ministro de Educación Nacional seguía con la inauguración del campo de deportes universitario, la toma de posesión del Palacio del Marqués de las Dos Aguas, adquirido por el Estado en 1949 para ubicar el Museo Nacional de Cerámica. La noticia termina con la inauguración de la nueva Facultad de Medicina, que como destacaban los titulares de la prensa era el principal acto que presidió el ministro José Ibáñez en su estancia en Valencia (Levante, 11-12-1949, p. 1). Sin duda, la inauguración de la Facultad de Medicina fue el aspecto a que dedicó más atención la prensa local de esta visita.

A partir de las dos noticias del NO-DO analizadas sobre inauguraciones de escuelas por parte del Ministro de Educación Nacional, José Ibáñez Martín, una en Barcelona y la otra en Valencia, podemos destacar el patrón que las inauguraciones de escuelas son actos complementarios al principal cometido de su visita en dos capitales de la periferia peninsular. Un claro signo de la importancia secundaria que desde el Ministerio de 
Educación Nacional se dio a las construcciones escolares en esta etapa del nacionalcatolicismo.

\section{Los ministerios de Ruiz-Giménez, Rubio García-Mina y Lora Tamayo (1951- 1968)}

En el período de 1951 a 1968, es el de transición desde el totalitarismo nacionalcatólico a la tecnocracia autoritaria. Al frente del Ministerio de Educación Nacional (denominado Ministerio de Educación y Ciencia a partir de 1966) se sucedieron tres ministros: Joaquín Ruiz-Giménez, Miembro de la Asociación Nacional Católica de Propagandistas, desde julio de 1951 a febrero de 1956; Jesús Rubio Gracia-Mina, que había sido subsecretario del Ministerio con Ibáñez Martín, desde febrero de 1956 a julio de 1962, y Manuel Lora Tamayo, miembro del Opus Dei, cuyo mandato finalizó en abril de 1968.

En general, durante este período no hubo modificaciones básicas respeto a la etapa de José Ibáñez al frente del Ministerio de Educación Nacional, en una combinación de continuidad y algún cambio. Dos nuevos rasgos, que se yuxtaponen al período anterior, son

el tímido reforzamiento del papel o función del Estado en la enseñanza y la racionalidad tecno-burocrática o tecnocracia economicista. Muestras del primer rasgo serían el relanzamiento de las construcciones escolares, la creación de centros estatales de bachillerato y, sobre todo, el incremento del porcentaje asignado al Ministerio de Educación en los presupuestos generales del Estado. (VIÑAO, 2004, p. 70)

En consonancia con estos cambios, en relación a los NO-DO en los que el Ministro de Educación protagoniza una inauguración de una escuela encontramos también otro cambio, el de poner en relieve y visibilizar la política de construcciones escolares del ministerio.

El 18 de julio de 1951 Joaquín Ruiz-Giménez es nombrado Ministro de Educación Nacional. Él era un catedrático de filosofía del derecho, que había sido embajador de España ante la Santa Sede y, como su antecesor en el cargo, era miembro de la Asociación Nacional Católica de Propagandistas. Ruiz-Giménez es persona conocida por un cierto 
aperturismo a nivel universitario, con la introducción de criterios menos políticos y más objetivos en la obtención de las cátedras. También es conocida su actitud antifranquista en los años finales del régimen dictatorial, así como por ser el primer Defensor del Pueblo en el año 1982, en los inicios del régimen democrático en España. Señalar que el mandato de Ruiz-Giménez estuvo marcado por la problemática universitaria, con medidas liberalizadoras y disturbios estudiantiles que pusieron fin a su cargo, pero el verdadero centro su política educativa no fue la universidad, sino la enseñanza media (DELGADO, 1994, p. 852).

Durante los cinco años de su mandato, el ministro Ruiz-Giménez contempló el déficit escolar a través de la Ley de Construcciones Escolares, de 22 de diciembre de 1953, que supuso un cambio fundamental en el papel a desempeñar por el Estado en este campo. “Tras un largo periodo de inhibición estatal, posterior a la II República, el Estado asumía de nuevo el papel de promotor directo de la construcción de escuelas, sólo o en convenio con los ayuntamientos" (VIÑAO, 2004, p. 73). Pero tal como sigue explicando Antonio Viñao, las escasas cifras de unidades escolares creadas reflejan una "continuidad inhibicionista" que perduraría hasta 1956 con la aprobación de una emisión de deuda pública de 2.500 millones de pesetas para construcciones escolares y la creación en 1957 de la Junta Central de Construcciones Escolares, ya fuera del mandato de Ruiz-Giménez. Esta continuidad inhibicionista también se puede apreciar en los NO-DO, porqué las noticias del Ministro de Educación, Ruiz-Giménez, inaugurando escuelas, continúan con un escaso protagonismo.

Tres meses después de tomar posesión de su cargo, el Ministro de Educación Joaquín Ruiz-Giménez inauguró, el 9 de octubre de 1951, el internado de la escuela municipal Virgen de la Paloma de Alcalá de Henares, una ciudad cercana a Madrid ( $A b c, 9$ 10-1951, p. 25). El acto fue recogido por el noticiario de NO-DO número $459 \mathrm{~B}$, del que no se ha conservado el audio. Se trata de otro de los escasos ejemplos de noticias del NO-DO de inauguración de escuelas protagonizadas por un Ministro de Educación. A diferencia de la noticia anteriores, el protagonismo de las autoridades en las imágenes es reducido, hay diversos planos cortos del ministro, pero toman más protagonismo las instalaciones del centro, un aula iluminada con filas de pupitres y con la simbología de la escuela nacional católica en sus paredes, el crucifijo y el retrato de Franco. También se muestra 
extensamente una exhibición de gimnasia en el patio del centro, con imágenes de niños haciendo ejercicios en formación con los brazos y las piernas. Este tipo de demostración gimnastica está muy asociada a los internados y es por este motivo que no nos extraña encontrarla en este noticiario.

El internado de la Virgen de la Paloma es la única noticia del NO-DO sobre la inauguración de una escuela presidida y protagonizada por Joaquín Ruiz-Giménez. Lo encontramos en otras inauguraciones, pero acompañando a Francisco Franco y en las que pasa desapercibido, como la inauguración en 1953 de un grupo escolar en Burgos (NO-DO, 553 B, 10-8-1953). Solo o acompañado a Franco, la participación del ministro Ruiz-Giménez en los NO-DO sobre inauguraciones de escuelas es muy reducida. Una falta de protagonismo que está muy acorde con la escasa intervención del Ministerio de Educación Nacional en la construcción de grupos escolares.

Con una universidad agitada, el 16 de febrero de 1956 el falangista Jesús Rubio García-Mina substituye a Ruiz-Giménez en el cargo de Ministro de Educación Nacional. Dentro de las familias políticas del franquismo, los falangistas obtuvieron el Ministerio de Educación Nacional, que hasta entonces había estado en manos de ministros de la familia católica. Jesús Rubio nombro como director general de enseñanza primaria a Joaquín Tena, un experto en estadística del Ministerio de Educación, que recopilando numerosos datos elaboró el primer mapa escolar español. Con pocas declaraciones públicas y pocas disposiciones oficiales, el tándem Rubio-Mena consiguió llevar a cabo por primera vez durante el franquismo una política planificada de construcciones escolares, con un Plan de Construcciones Escolares de 1956 (en realidad se desarrolló a partir del 1957) que quedó corto a causa de las dificultades para obtener recursos económicos (NAVARRO, 1990, p.169).

La existencia de una política pública construcciones escolares queda reflejada en el NO-DO, con noticias que dan a conocer los planes constructivos del Ministerio de Educación y sus resultados. A diferencia de los NO-DO anteriores, a partir de estos años las noticias sobre inauguraciones de escuelas son de conjunto, en el sentido que se da información sobre más de una escuela, cuando antes tenía más importancia la inauguración de un edificio escolar singular. 
El NO-DO 787 A, de 2 de febrero de 1958, contiene la noticia sobre la exposición del Plan Quinquenal de Construcciones Escolares (1957-1961) situada en la Biblioteca Nacional en Madrid. Una exposición inaugurada por el Ministro de Educación Jesús Rubio el 25 de enero de 1958. Durante el acto el director general de Primaria Joaquín Tena, verdadero promotor de aquella exposición explicó sus detalles al ministro ( $A b c, 26-01-1958$, p.39). La noticia del NO-DO al respecto parece posterior al día de la inauguración, porque en ella no aparece el ministro Jesús Rubio, sí que sale el director general de Primaria acompañado de periodistas, la voz en off dice "a esta exposición realizan una visita los periodistas madrileños a quienes el director general de enseñanza Primaria, Don Joaquín Tena, explicó la extensión de esta labor iniciada en España el pasado año”. En lo que parece una visita preparada para los medios de comunicación posterior a la inauguración.

La noticia da un sinfín de cifras a través de la locución y los gráficos que forman parte de la exposición, como por ejemplo sobre la reducción del analfabetismo en España, o la construcción de escuelas en cada provincia española. Se trata de un claro intento de lanzar un mensaje de solvencia de la política gubernamental respeto la construcción de escuelas. Entre las cifras destaca la de las escuelas nuevas que se prevén construir, que se cifra en 24.826. Una cantidad asombrosa, que pretende deslumbrar al espectador, pero que en realidad era insuficiente respeto a las necesidades que tenía España. En noticiario de este NO-DO no decía que este esfuerzo estaba lastrado por la insuficiencia presupuestaria en gastos educativos (RODRíGUEZ, 2008, p. 175). Para conseguir la plena escolarización, según informes de la inspección escolar de la época, además de construir esas casi 25.000 escuelas nuevas, había la necesidad de substituir unas 17.000 más que se encontraban en locales con malas condiciones, lo que eleva la cifra a unas 42.000 escuelas necesarias (LÁZARO, 1975, p. 120).

El NO-DO 931C, de 7 de noviembre de 1960, trata otra vez de una exposición en Madrid sobre el Plan Nacional de Construcciones Escolares en la noticia titulada "Operación Escuela". En este caso el ministro Jesús Rubio aparece en las imágenes de la inauguración de la exposición, conjuntamente con el director general de enseñanza Primaria y otras autoridades. La noticia mantiene un tono muy optimista, no menciona las dificultades presupuestarias, la locución afirma que el desarrollo del plan de construcciones escolares 
"podrá resolver en forma definitiva y en plazo breve el problema fundamental de la enseñanza primaria". Mientras que las imágenes muestran maquetas de escuelas, fotografías de aulas y material pedagógico.

En julio de 1962 fue nombrado Ministro de Educación Nacional (de Educación y Ciencia a partir de 1966) al profesor de química Manuel Lora Tamayo, hombre bien conocido en los ambientes científicos. Lora Tamayo fue uno de los ministros tecnócratas, más expertos que políticos, que desembarcaron en el gobierno de Franco. Bajo su mandato, el Ministerio de Educación se dedicó al campo universitario y científico, pero también a la enseñanza primaria. Puso al día la legislación sobre construcciones escolares y aumentó las aportaciones del Estado en este tema. Sobre las construcciones escolares Lora Tamayo puso el acento en el papel de los municipios, intentando ayudar aquellos que tenían dificultades, pero "destacó en más de una ocasión, en sus discursos claves, la tozudez y la desidia de no pocos municipios que afirmaban no tener dinero para construir escuelas" (NAVARRO, 1990, p. 217).

El Ayuntamiento de Madrid no estaba entre los municipios que no se responsabilizaba de la construcción de centros escolares, en unos años de gran crecimiento demográfico, la corporación municipal y el ministerio hacían los deberes según la propaganda de la época. Este era un mensaje implícito en el NO-DO 1081 B, de 23 de setiembre de 1963, sobre la inauguración en diversos barrios de Madrid de 20 nuevos grupos escolares. El acto es presidido por los ministros de Educación y Vivienda, Manuel Lora-Tamayo y Martínez Sánchez-Arjona respectivamente, el alcalde de Madrid José Finat y otras autoridades, entre las que destacamos al director general de enseñanza Primaria, Joaquín Tena. Los grupos escolares inaugurados formaban parte de la primera fase del Plan de Construcciones Escolares de Madrid, en el que el Ministerio de Educación y el Ayuntamiento contribuyeron cada uno con el 50\% de los gastos de edificación (Abc, 17-091963, p. 21). La comitiva recorrió los diversos centros para inaugurarlos, con bendición incluida, iniciando el recorrido en el poblado de Fuencarral, siguiendo por los barrios de Ventilla, Canillas, Gran San Blas, Valdecanillas y calle Amposta. Especial relevancia se dio a la inauguración del grupo escolar del barrio de Moratalaz, construido en homenaje al ejército español. Al final se inauguraron los grupos escolares del barrio de San Cristóbal de 
los Ángeles y la colonia del Manzanares. En total 10 barrios de Madrid, cuando el titular del NO-DO habla de 20 grupos escolares, en lo que parece ser una multiplicación interesada por aumentar el número de escuelas inauguradas, considerado posiblemente como diferentes las de niños y las de niñas de cada grupo escolar.

Las imágenes del NO-DO muestran escenas de la comitiva de autoridades visitando algunas de estas escuelas, se recrean en la inauguración de Moratalaz, muestran aulas y material escolar. La voz en off destaca que "los nuevos bloques disponen de 350 clases en las que recibirán enseñanza 14.000 niños madrileños", la locución termina con estas palabras "con estos nuevos edificios escolares y otros de inmediata inauguración se incrementa notablemente el Plan de Enseñanza Primaria Nacional.” En conjunto el NO-DO refleja que en enseñanza primaria se ha alcanzado de lleno la tecnocracia, la cinta nos muestra aulas equipadas adecuadamente, expone datos y la idea que el problema de la falta de plazas escolares está en vías de solución. Mantiene aún algún rasgo del nacionalcatolicismo, dando importancia al ejército español y mostrando imágenes religiosas de los nuevos centros escolares.

En resumen, en esta etapa de transición del nacionalcatolicismo a la tecnocracia, los noticiarios del NO-DO con la inauguración de centros escolares pasaran de ser noticias con información de un centro escolar único y singular a convertirse en información sobre planes de construcciones escolares y la apertura de más de un grupo escolar. Una consecuencia de la existencia de planes generales en el Ministerio de Educación, que se querían difundir a través del NO-DO de forma propagandística, porqué a pesar de algún avance en el tema, seguían muchas restricciones de tipo presupuestario, que no permitieron conseguir los objetivos propuestos.

\section{Ley General de Educación de 1970 bajo el ministerio de Villar Palasí}

El 18 de abril de 1968, José Luis Villar Palasí, un catedrático de universidad afín al Opus Dei, fue nombrado Ministro de Educación y Ciencia, cargo que ocupó hasta 1973. El principal acontecimiento en la política educativa de estos años fue la Ley General de Educación y Financiamiento de la Reforma Educativa, de 4 de agosto de 1970. La 
elaboración y desarrollo de esta ley marco el sistema educativo en los años finales de la dictadura y de la transición a la democracia en España, a la vez que fue el principal tema de política educativa tratado en los noticiarios del NO-DO. En este aparatado final trataremos a través del NO-DO como el ministro Villar Palasí abordo las construcciones escolares. Él no fue el último Ministro de Educación del franquismo, pero con él terminamos el artículo, ya que los ministros contrareformistas que lo sucedieron no tuvieron una presencia significativa en los NO-DO de inauguraciones de nuevas escuelas. No en vano casi la mitad de los puestos escolares que se crearon en 1974 presentaban deficiencias cualitativas por estar en aulas prefabricadas o turnos dobles (MAYORDOMO, 1999, p. 33).

Con la llegada en 1968 de Villar Palasí al Ministerio de Educación se inicia un nuevo plan de desarrollo escolar (1968-1971), que a partir de un estudio previo cifraba en un millón la necesidad de nuevos puestos escolares a crear en España (LÁZARO, 1975, p. 124). La concepción del edificio escolar evolucionó con la reforma educativa resultado de la Ley General de Educación, desde 1971 fue obligatorio un modelo de edificio escolar, con aulas y espacios de diferentes dimensiones, más flexibles, que permitieran superar la enseñanza magistral. También se iniciaron los planes de urgencia, que debían permitir eliminar o reducir el déficit escolar en aquellas zonas del país donde era más grave. Los noticiarios del NO-DO casi no reflejaron estos últimos aspectos, incluidos en la reforma educativa, mientras que con relación a las construcciones escolares el NO-DO continuaba con el mensaje desarrollista, de cubrir las necesidades de plazas escolares con escuelas bien equipadas.

En el noticiario del NO-DO número 1345 A, de 14 de octubre de 1968, Francisco Franco en persona, acompañado por su esposa, el Ministro de Educación, Villar Palasí, el alcalde de Madrid, Arias Navarro y otras autoridades inauguran en Madrid el grupo escolar de Nuestra Señora de la Concepción y visitan una exposición sobre el plan de desarrollo o de construcciones escolares (1968-1971). En este acto también se inauguró oficialmente el curso 1968-1969 de enseñanza primaria en España, era la primera vez que Franco presidía esta inauguración, pero en el NO-DO no se menciona ni contempla el inicio oficial del curso de enseñanza primaria en España. En este noticiario destaca, una vez más, la presencia de Franco y su esposa, acaparando el protagonismo y las imágenes de la comitiva de 
autoridades. Los dos reciben una placa conmemorativa de plata por parte de dos alumnos de la escuela, en una escena con gran expectación, pero sin las muestras de fervor multitudinario de otros noticiarios. Este NO-DO dedica algunas imágenes a mostrar unas instalaciones del nuevo colegio inaugurado que califica de "adecuadas". El otro tema destacable del noticiario es la inauguración de la exposición sobre el plan de desarrollo escolar, con mapas de situación y numerosas fotografías de escuelas construidas en España. Franco “inaugura simbólicamente" 4.184 escuelas distribuidas por toda la geografía española, que según la voz en off aseguran la educación primaria a 168.000 alumnos.

El ministro Villar Palasí pasa muy desapercibido en las imágenes del NO-DO, detrás de Franco, el noticiario no recoge el discurso que pronunció el Ministro de Educación con motivo de la apertura oficial del nuevo curso de enseñanza primaria en España, la locución no menciona en ningún momento que eran los actos oficiales de inicio del curso escolar 1968-1969. La prensa escrita sí informa detalladamente sobre la participación de Villar Palasí en aquellos actos de inauguración del curso escolar. La noticia es portada de $A b c, 3$ de octubre de 1968, en el interior del diario se recoge el discurso de Villar Palasí. Su discurso no peca de modestia, empiezan por considerar como "eficaz" la obra del gobierno con la inauguración de 4.184 aulas y sigue explicando la política sobre enseñanza primaria del Ministerio de Educación, que pasa por la promoción de construcciones escolares y la formación de los maestros. Sobre la idea, según sus palabras, que era

necesario desarrollar una política que se oriente a extender los beneficios de la educación y, paralelamente, a mejorar su nivel y calidad. El derecho fundamental a la igualdad de oportunidades de todos los españoles, debe transformarse en el ideal motor de esta empresa a la que de ningún modo podemos renunciar. (Abc, 3-10-1938, p. 33)

Con una política de generalizar la escolarización básica, a través de nuevas construcciones escolares, el ministro Villar Palasí protagonizó noticiarios del NO-DO que recogen inauguraciones de nuevas escuelas, situadas en las ciudades más pobladas del territorio, donde había gran déficit de plazas escolares, como es el caso de la periferia de 
Madrid. El NO-DO 1403 B, de 24 de noviembre de 1969, contiene como primera noticia la inauguración por parte de Villar Palasí de 7 nuevas escuelas en Madrid. El Ministro de Educación aparece en diversas secuencias, fuera del edificio y dentro de algunas aulas con alumnos, va acompañado del alcalde de Madrid, Carlos Arias Navarro y otras personalidades. En un aula Villar Palasí se dirige a unas niñas sentadas en su mesa, una escena de proximidad a los alumnos que nunca antes se había visto en el NO-DO. Un acto que refleja un talante diferente del ministro respecto a sus predecesores, que protagonizaban según los NO-DO unas inauguraciones más protocolarias, en las que rara vez aparecían alumnos y menos conversaban con el ministro. La locución explica que las 7 nuevas escuelas de Madrid "vienen a resolver en parte el acuciante problema de la escolarización en la capital de España". Una frase que dista un poco del triunfalismo expresado en otros NO-DO, porque dice que el problema solo se resuelve "en parte". La voz en off añade que estas 7 escuelas están dotadas de las más modernas instalaciones y materiales pedagógicos y que forman parte de un plan que pretende crear más de 100.000 puestos escolares en la capital de España de los cuales 52.200 estaban ya en funcionamiento. Unas cifras que quieren hacer creer al espectador que el problema está encauzado y en vías de solución.

Una información similar a la de Madrid, sin la presencia del ministro y menos crítica, se fija en Barcelona, donde también había problemas por la falta de plazas escolares. El NODO 1363 B, del 17 de febrero de 1969, trata sobre la construcción por parte del ayuntamiento de 5 nuevos centros escolares en Barcelona, para "resolver los problemas de la enseñanza". La información detalla las cifras de centenares de alumnos de cada uno de los centros escolares y termina con una noticia sobre un moderno comedor escolar en autoservicio.

A partir del año 1970, con la aprobación de la Ley General de Educación, los noticiarios del NO-DO dejan de contener noticias sobre inauguraciones de centros escolares. La importante reforma educativa impulsada por el ministro José Maria Villar Palasí, centra los contenidos de los NO-DO referentes a la enseñanza. Los dos noticiarios NO-DO números 1414 A y 1414 B, del 9 de febrero de 1970 tratan sobre la propuesta de ley, prestan más atención a los cambios en los niveles educativos y metodológicos en la 
enseñanza que en las construcciones escolares. El primer noticiario, NO-DO 1414 A, empieza con la inauguración de la exposición "El reto de nuestro tiempo" por parte de Franco, con la asistencia de Villar Palasí y otras autoridades. Una exposición sobre "construcciones y realizaciones del Ministerio de Educación”, con maquetas estadísticas y mapas. La noticia expone que se hace urgente una transformación de la educación, tal como señala el "Libro Blanco" realizado al respecto. Sobre construcciones escolares el NO-DO tan solo se menciona que existían escuelas vacías en el campo y falta de puestos escolares en las ciudades, en lo que se basará la política de concentraciones escolares en centros urbanos que desarrolló el Ministerio de Educación. El segundo noticiario, NO-DO 1414 B, trata sobre las diferentes etapas educativas, remarcando los cambios pedagógicos, mientras que sobre construcciones escolares tan solo se afirma que "en todo el país surgirán los centros necesarios con prioridad absoluta para las comarcas de población obrera industrial o agrícola".

Unos años después, ya en plena reforma educativa, en 1972 se inauguró en Madrid por parte del Ministro de Educación José Maria Villar Palasí la exposición “La reforma educativa en marcha", noticia que recoge el NO-DO 1520 A de 21 de febrero. Esta exposición recoge la labor realizada desde la aprobación de la Ley General de Educación, en ella se muestran maquetas de edificios de las nuevas universidades, abundante material didáctico y mapas sobre la labor realizada. En esta ocasión, las referencias a construcciones escolares en el NO-DO son inexistentes. Resultado de una reforma que transformó técnicamente el sistema educativo español, las construcciones escolares dejaban de ser el principal tema sobre las noticias del NO-DO sobre enseñanza primaria en las que participaba el Ministro de Educación.

Termina así un largo recorrido por los noticiarios del NO-DO sobre escuelas de educación primaria que visita directamente, o a través de exposición, el Ministro de Educación. Un recorrido que empieza con unos NO-DO en que la inauguración de escuelas singulares es una parte secundaria en un conjunto de actos protocolarios, continua más adelante con el desarrollo de planes de construcciones escolares y la inauguración de conjuntos de escuelas, para terminar en los años de la Ley General de Educación, donde como acabamos de ver, el tema de las construcciones escolares desaparece de los NO-DO. 
En fin, un reflejo de la política del Ministerio de Educación con la participación del ministro vista, etapa a etapa, en los noticiarios propagandísticos del NO-DO.

\section{Referencias}

CASANOVAS, Josep \& COLLELLDEMONT, Eulàlia. La fachada de la escuela. La imagen de la enseñanza en los films documentales de inauguración de grupos escolares durante la dictadura de Primo de Rivera. En: DÁVILA, Paulí \& NAYA, Luis María (Eds.). Espacios y patrimonio histórico-educativo. San Sebastián: Erein, 2016, p. 663-678.

CASANOVAS, Josep \& PADRÓS, Núria. Pizarra y pupitre. La representación de la práctica escolar a través del NO-DO en las inauguraciones de escuelas durante franquismo. En: GONZÁLEZ, Sara; MEDA, Juri; MONTILLA, Xavier \& POMANTE, Lugiaurelio (Eds.). La práctica educativa. Historia, memoria y patrimonio. Salamanca: FahrenHouse, 2018, p. 697-706.

CORBERA, Mireia; MOREJÓN, Anna \& OLSINA, Sandra. Han bombardejat una escola! Documental, 2010. Disponible en: < https://www.youtube.com/watch?v=5VLUfP_tUol>. Acceso: 21-1-2020.

DELGADO, Buenaventura (Coord.). Historia de la educación en España y América. La educación en la España contemporánea (1789-1975). Madrid: Ediciones SM, 1994, vol. 3.

GÓMEZ GARCÍA, Claudia. La pelota vasca y el NO-DO: un símbolo vasquista a través del noticiario cinematográfico franquista. Sancho el sabio. Revista de cultura e investigación vasca, n. 38, p. 117-136, 2015.

GUTIÉRREZ, Carlos; JIMÉNEZ, Ander; GÓMEZ, María Teresa \& IZQUIERDO, Eugenio, Martial arts and combat sports in the Spanish No-Do newsreels. RAMA. Revista de Artes Marciales Asiáticas, v. 11, n. 2, p. 108-109, 2016.

HERNÁNDEZ ROBLEDO, Miguel Ángel. Estado e información. El NO-DO al servicio del Estado Unitario (1943-1945). Salamanca: Servicio de Publicaciones de la Universidad Pontificia de Salamanca, 2003.

LÁZARO, Emilio. Historia de las construcciones escolares en España. Revista de Educación, n. 240, p. 114-126, 1975. 
MAYORDOMO, Alejandro. Aproximación a enfoques y tiempos de la política educativa, En: MAYORDOMO, Alejandro (Coord.) Estudios sobre la política educativa durante el franquismo. Valencia: Universitat de València, 1999.

MOLINA, María Dolores \& SANCHIDRIÁN, Carmen. La sección Femenina y la educación de las mujeres vistas a través del NO-DO. Comunicación presentada en X Encuentro de Investigadoras e Investigadores del Franquismo, Universitat de València, 2019, (en prensa).

MUVIP Museu Universitari Virtual de Pedagogia. Resultats de recerca del proyecto de investigación ARAEF. Disponible en: <https://www.uvic.cat/museuvirtual/investigacions/araef>. Acceso en: 3-2-2020.

NAVARRO, Ramón. La enseñanza primaria durante el franquismo (1936-1939). Barcelona: PPU, 1990.

RODRÍGUEZ MARTÍNEZ, Saturnino. EI NO-DO, catecismo social de una época. Madrid: Editorial Complutense, 1999.

RODRÍGUEZ MATEOS, Araceli. Un franquismo de cine. La imagen política del Régimen en el noticiario NO-DO (1943-1959). Madrid: Ediciones Rialp, 2008.

SIMÓN, Juan Antonio. El deporte en el No-Do durante el primer franquismo 1943-1951. Hispania Nova, n. 17, p. 341-371, 2019.

TRANCHE, Rafael R \& SÁNCHEZ-BIOSCA, Vicente. NO-DO. El tiempo y la memoria. ( $8^{\mathrm{a}}$ ed). Madrid: Ediciones Cátedra, Filmoteca Española, 2006.

TUÑÓN de LARA, Manuel. Prólogo. En: NAVARRO, Ramón. La enseñanza primaria durante el franquismo (1936-1939). Barcelona: PPU, 1990, p. 17-21.

VIÑAO, Antonio. Escuela para todos. Educación y modernidad en la España del siglo XX. Madrid. Marcial Pons, 2004.

VIÑAO, Antonio. La educación en el franquismo (1936-1975). Educar em Revista, n. 51, p. 19-35, 2014.

VIÑAO, Antonio. El plan quinquenal de construcciones escolares de 1957-1961. Propaganda, ideologies and education. ARAEFweb, 2018. 


\section{Referencias de los NO-DO}

Relación de los noticiarios de los NO-DO con el título de la noticia analizada según el programa de mano, citadas en el texto del artículo y ordenadas por orden cronológico.

NO-DO, N 259 A, 22-12-1947, Construcciones españolas. Inauguración de diversos edificios en la villa de Puebla de la Sierra. Ayuntamiento, Juzgado, Iglesia y Escuela. Disponible en: <http://www.rtve.es/filmoteca/no-do/not-259/1467623/>. Acceso en 6-03-2020.

NO-DO, N 309 A, 6-12-1948, Barcelona. A bordo del cañonero "Pizarro" llegan las Reliquias de San José de Calasanz. Disponible en: <http://www.rtve.es/filmoteca/nodo/not-309/1487630/>. Acceso en 6-04-2020.

NO-DO, N 310 A, 13-12-1948, Barcelona. El Ministro de Educación Nacional inaugura la nueva Escuela del Mar. Disponible en: <http://www.rtve.es/filmoteca/no-do/not310/1467231/>. Acceso en 6-04-2020.

NO-DO, N 364 B, 26-12-1949. Valencia. El Ministro de Educación Nacional en tierras del Turia. Inauguración del grupo escolar Teodoro Llorente y del campo de deportes de la ciudad universitaria. Toma de posesión del Palacio de Dos Aguas. En la Facultad de Medicina. Disponible en: <http://www.rtve.es/filmoteca/no-do/not-364/1468088/>. Acceso en 7-04-2020.

NO-DO, N 459 B, 22-10-1951. Alcalá de Henares. La nueva residencia del Colegio Municipal Nuestra Señora de la Paloma. El Ministro de Educación Nacional preside el acto inaugural. Disponible en: < http://www.rtve.es/filmoteca/no-do/not-459/1469492/>. Acceso en: 8-04-2010.

NO-DO, N 553 B, 10-8-1953. Franco en Burgos. El Generalísimo inaugura una fábrica de papel moneda. Un nuevo grupo escuela que albergará a un millar de alumnos. Disponible en: <http://www.rtve.es/filmoteca/no-do/not-553/1487703/>. Acceso en 30-3-2020.

NO-DO, N 564 A, 26-10-1953. Cádiz. S.E. el Jefe del Estado inaugura un nuevo grupo escolar y una estación frigorífica. Homenaje popular en la Plaza de San Juan de Dios. Disponible en: <http://www.rtve.es/filmoteca/no-do/not-564/1483561/>. Acceso en 30-32020.

NO-DO N 787 A, 2-02-1958. Construcciones Escolares. En la Biblioteca Nacional de Madrid. Exposición del Plan Quinquenal. Disponible en:

<http://www.rtve.es/filmoteca/no-do/not-787/1486260/>. Acceso en 7-4-2020.

NO-DO N 931 C, 7-11-1960. Operación Escuela. Bajo la presidencia del Ministro de Educación Nacional. Se inaugura una exposición en el Ministerio de la Vivienda. Disponible en: <http://www.rtve.es/filmoteca/no-do/not-931/1469780/>. Acceso en 7-42020. 
NO-DO N 1081 B, de 23-09-1963. Veinte nuevos Grupos Escolares en Madrid. Inauguración por los Ministros de Educación Nacional y Vivienda. Disponible en:

<http://www.rtve.es/filmoteca/no-do/not-1081/1468846/>. Acceso en 8-4-2020.

NO-DO N 1345 A, 14-10-1968. Nuevo Curso de Enseñanza Primaria. Colegios Nacionales inaugurados por S.E. el Jefe del Estado. Disponible en: <http://www.rtve.es/filmoteca/nodo/not-1345/1486405/>. Acceso en 14-4-2020.

NO-DO N 1363 B, 17-02-1969. Nuevos Grupos Escolares en Barcelona. Autoservicios en las Escuelas Públicas. Disponible en: <http://www.rtve.es/filmoteca/no-do/not1363/1487036/>. Acceso en 15-04-2020.

NO-DO N 1403 B, 24-11-1969. Nuevos Centros Escolares en Madrid. El Ministro de Educación y Ciencia y el Alcalde en la inauguración. Disponible en:

<http://www.rtve.es/filmoteca/no-do/not-1403/1486675/ >. Acceso en 15-04-2020.

NO-DO N 1414 A, 9-02-1970. El Reto de Nuestro Tiempo. Franco inaugura una exposición de Enseñanza. Aspectos del "Libro Blanco". Disponible en:

<http://www.rtve.es/filmoteca/no-do/not-1414/1486749/>. Acceso en 15-04-2020.

NO-DO 1414 B, 9-02-1970. Año Internacional de Educación. España presenta a las Cortes un nuevo Plan. "El Libro Blanco". Disponible en: <http://www.rtve.es/filmoteca/nodo/not-1414/1486753/ >. Acceso en 15-04-2020.

NO-DO 1520 A, 21-02-1972. La reforma educativa en marcha. Interesante muestra de la labor realizada desde la aprobación de la Ley. Disponible en:

<http://www.rtve.es/filmoteca/no-do/not-1520/1469374/>. Acceso en 15-04-2020.

NO-DO, N 1558 A, 13-11-1972, Información nacional. La "Escuela del Mar", del Ayuntamiento de Barcelona. Una institución docente modelo. Disponible en: <http://www.rtve.es/filmoteca/no-do/not-1558/1470742/>. Acceso en 6-04-2020.

Recebido em: 30/03/2020

Aprovado em: 22/05/2020

Universidade do Estado de Santa Catarina - UDESC Programa de Pós-Graduação em Educação - PPGE

Revista Linhas

Volume 21 - Número 47 - Ano 2020 revistalinhas@gmail.com 